\title{
.
}

\section{INSTRUMENTOS Y FACILIDADES FINANCIERAS DE LA ACCIÓN EXTERIOR DE LA UNIÓN EUROPEA Situación actual y propuesta de reforma para el periodo $2021-2027$}

La Unión Europea ocupa un papel protagonista en la cooperación al desarrollo a nivel internacional con financiación de proyectos a través de diferentes instrumentos y modalidades de ejecución. El presente documento repasa el conjunto de instrumentos y facilidades financieras de la acción exterior comunitaria existente en el marco plurianual actual, con especial referencia a la modalidad de blending y al fondo de garantía del nuevo Plan Europeo de Inversiones Exteriores, haciendo también mención a la actividad del Banco Europeo de Inversiones en terceros países. Finalmente, se introduce la propuesta de la Comisión de cara al nuevo marco plurianual para el periodo 2021-2027.

Palabras clave: ayuda externa, cooperación al desarrollo, financiación al desarrollo, cooperación delegada, blending, Banco Europeo de Inversiones.

Clasificación JEL: F15, F30, F35, G15, O19.

\section{Introducción}

Mediante su ayuda externa, la Unión Europea (UE) contribuye a impulsar el desarrollo de los países no comunitarios, con un papel protagonista a nivel mundial en la financiación de proyectos. En el marco financiero plurianual (MFP) para el periodo 2014-2020 la acción exterior de la UE tiene asignado un volumen total de recursos de 96.768 millones de euros, resultado de conjugar los 66.262 millones contemplados en el capítulo IV, «Europa Global», del

\footnotetext{
* Técnico Comercial y Economista del Estado.

Versión de agosto de 2018.
}

Presupuesto de la UE para el conjunto del periodo, con los 30.506 millones de carácter extrapresupuestario contemplados en el Fondo Europeo de Desarrollo (FED).

Los fondos asignados a la acción exterior se destinan a la financiación de programas y proyectos a través de un conjunto heterogéneo de instrumentos y facilidades financieras que ha ido evolucionando en línea con los objetivos de contribución al desarrollo, el proceso de integración comunitaria y la evolución de las prioridades y relaciones exteriores de la UE, junto con los principios de eficiencia, adicionalidad y apalancamiento.

Habiéndose alcanzado un volumen destacado en el conjunto de recursos dirigidos a la $D$ 
acción exterior, una parte importante de estos es ejecutada mediante gestión indirecta o delegada, a través de agencias internacionales e instituciones homologadas por la Comisión -con experiencia en la gestión de fondos y presencia sobre el terreno-, incluyendo el uso de nuevas modalidades de financiación combinada.

Por su parte, el Banco Europeo de Inversiones (BEI) destina en torno al 10 por 100 de su actividad a la financiación de proyectos de inversión en países no comunitarios con el objetivo de contribuir a su avance y desarrollo.

De cara a la aprobación del nuevo marco financiero plurianual 2021-2027, la Comisión Europea (CE) ha presentado una propuesta que implica cambios relevantes en los instrumentos existentes en la actualidad, como la «presupuestarización» del FED —en un contexto de salida del Reino Unido de la UE-, o la búsqueda de una mayor simplificación al contemplar la creación de un nuevo instrumento amplio con un enfoque multidisciplinar, integrando varios de los existentes en el marco actual, pasando a ser el instrumento de referencia para el nuevo periodo plurianual.

\section{Volumen de recursos, instrumentos y reparto geográfico y sectorial}

El volumen total de recursos destinados a la acción exterior comunitaria en el periodo 20142020 — de 96.768 millones de euros ${ }^{1}$ — sitúa a la UE como uno de los principales donantes a nivel internacional ${ }^{2}$. En la actualidad, la acción exterior comunitaria se encuentra bajo el capítulo IV, «Europa Global», del presupuesto comunitario, que contiene el 68,5 por 100 del

\footnotetext{
1 A precios corrientes.

2 El tercero, tras Estados Unidos, Alemania y Reino Unido - primero, teniendo en cuenta a la UE y EEMM en conjunto-.
}

volumen total, completado por los recursos de carácter extrapresupuestario procedentes del FED a partir de las aportaciones de los Estados miembros.

La ayuda externa se canaliza a través de instrumentos geográficos y temáticos. Los primeros se estructuran en función de las regiones de referencia de las relaciones exteriores de la UE (grupo de países de África, Caribe y Pacífico - ACP_, regiones de Vecindad -Este ${ }^{3}$ y Sur ${ }^{4}$ - países candidatos actuales y potenciales a la adhesión —en adelante países candidatos-y resto de países emergentes —de Asia, Oriente Medio, América Latina...-). Los segundos recogen diferentes áreas de actuación (procesos de paz, derechos humanos, desarrollo de acuerdos de asociación, ayuda humanitaria...). El Cuadro 1 recoge una tabla con el conjunto heterogéneo de instrumentos y partidas financieras para el periodo actual.

Las dos Direcciones Generales (DG) de la Comisión con una mayor implicación en la gestión de la acción exterior comunitaria son la DG de Desarrollo y Cooperación Internacional -DG DEVCO_, bajo cuyo ámbito se encuentra un 54,7 por 100 del total de la ayuda comunitaria comprometida ${ }^{5}$ (17 por 100 de origen presupuestario y 37,7 por 100 procedente del FED), y la DG de Vecindad y Ampliación -DG NEAR-, con un 25,6 por 100, repartiéndose el resto entre diferentes $D G$.

La media anual de recursos comprometidos en el periodo plurianual actual es de $13.824^{6}$ millones de euros. Con datos de los últimos $\square$

\footnotetext{
3 Armenia, Azerbaiyán, Bielorrusia, Georgia, Moldavia, Ucrania. Rusia no está incluida en la Política de Vecindad, pero puede recibir fondos de programas regionales del Instrumento Europeo de Vecindad.

4 Argelia, Egipto, Israel, Jordania, Líbano, Libia, Marruecos, Palestina, Siria y Túnez.

5 Datos de 2016, último ejercicio con datos completos publicados - a través del informe anual de gestión de los instrumentos financieros de acción exterior de la UE-.

6 A precios corrientes.
} 
CUADRO 1

INSTRUMENTOS FINANCIEROS DE LA ACCIÓN EXTERIOR DE LA UE-MFP 2014-2020

\begin{tabular}{|c|c|c|c|}
\hline Instrumentos y partidas financieras 2014-2020 & $\begin{array}{l}\text { Dotación en millones } \\
\text { de euros (1) }\end{array}$ & Media anual & $\begin{array}{c}\text { Peso } \\
\text { (en porcentaje) }\end{array}$ \\
\hline \multicolumn{4}{|l|}{ 1. Instrumentos geográficos } \\
\hline Fondo Europeo de Desarrollo Sostenible (FED-EDF) (2) & 30.506 & 4.358 & 31,5 \\
\hline África, Caribe y Pacífico (ACP) (3) & 29.089 & 4.156 & 30,1 \\
\hline Países y Territorios de Ultramar (PTU) & 365 & 52 & 0,4 \\
\hline Gastos administrativos & 1.053 & 150 & 1,1 \\
\hline Instrumento de Cooperación al Desarrollo (ICD-DCI) (4) & 19.662 & 2.809 & 20,3 \\
\hline Programas Regionales (4) & 11.809 & 1.687 & 12,2 \\
\hline Programa Panafricano & 845 & 121 & 0,9 \\
\hline Programas Temáticos (5) & 7.008 & 1.001 & 7,2 \\
\hline Instrumento Europeo de Vecindad (IEV-ENI) & 15.433 & 2.205 & 15,9 \\
\hline Instrumento Preadhesión (IPA) & 11.699 & 1.671 & 12,1 \\
\hline Instrumento para Groenlandia (IpG-IfG) & 218 & 31 & 0,2 \\
\hline \multicolumn{4}{|l|}{ 2. Instrumentos temáticos } \\
\hline Política Exterior y de Seguridad Común (PESC-CFSP) & 2.339 & 334 & 2,4 \\
\hline $\begin{array}{l}\text { Instrumento para la Contribución a la Estabilidad y la } \\
\text { Paz (IcEP-IcSP) }\end{array}$ & 2.339 & 334 & 2,4 \\
\hline $\begin{array}{l}\text { Instrumento Europeo para Democracia y Derechos } \\
\text { Humanos (IEDDH-EIDHR) }\end{array}$ & 1.333 & 190 & 1,4 \\
\hline $\begin{array}{l}\text { Instrumento de Partenariado o Cooperación con } \\
\text { Terceros Países (PI) }\end{array}$ & 955 & 136 & 1,0 \\
\hline $\begin{array}{l}\text { Instrumento de Cooperación en Seguridad Nuclear } \\
\text { (ICSN-INSC) }\end{array}$ & 225 & 32 & 0,2 \\
\hline $\begin{array}{l}\text { Iniciativa de Voluntarios de Ayuda Humanitaria de la } \\
\text { UE (VAUE-EUAV) }\end{array}$ & 148 & 21 & 0,2 \\
\hline Mecanismo de Protección Civil (MPC-CPM) & 145 & 21 & 0,1 \\
\hline Agencias descentralizadas & 154 & 22 & 0,2 \\
\hline Ayuda humanitaria & 6.621 & 946 & 6,8 \\
\hline \multicolumn{4}{|l|}{ 3. Asistencia financiera } \\
\hline Asistencia Macro-Financiera (MFA) (6) & 565 & 81 & 0,6 \\
\hline Fondo de Garantía para Acciones Exteriores (FG-GF) & 1.193 & 170 & 1,2 \\
\hline $\begin{array}{l}\text { Resto hasta el importe total de la rúbrica } 4 \text { «Europa } \\
\text { Global» del MFP 2014-2020 }\end{array}$ & 3.233 & 462 & 3,3 \\
\hline Total origen presupuestario MFP 2014-2020 & 66.262 & 9.466 & 68,5 \\
\hline Total extrapresupuestario MFP 2014-2020 & 30.506 & 4.358 & 31,5 \\
\hline Total MFP 2014-2020 (7) & 96.768 & 13.824 & 100,0 \\
\hline \multicolumn{4}{|l|}{ (1) Cifras en precios corrientes. } \\
\hline \multicolumn{4}{|l|}{ (2) Carácter extrapresupuestario. } \\
\hline \multicolumn{4}{|c|}{$\begin{array}{l}\text { (3) } 84 \text { por } 100 \text { Programas nacionales y regionales, } 12 \text { por } 100 \text { Cooperación interregional e Intra-ACP, } 4 \text { por } 100 \text { Facilidad de Inversión Gestionada por } \\
\text { el BEl. }\end{array}$} \\
\hline \multicolumn{4}{|c|}{$\begin{array}{l}\text { (4) Incluye los programas temáticos de Bienes Públicos y Desafíos Globales y de Organismos de la Sociedad Civil y Autoridades Locales, además del } \\
\text { Instrumento Panafricano. }\end{array}$} \\
\hline \multicolumn{4}{|c|}{$\begin{array}{l}\text { (5) Incluye el Programa de Bienes Públicos y Desafíos Globales(GPGC) - } 5.101 \text { millones de euros en el MFP-y el Programa de Organizaciones de } \\
\text { la Soc. Civil y Autoridades Locales (CSO-LA) - } 1.907 \text { millones de euros. }\end{array}$} \\
\hline \multicolumn{4}{|c|}{ (6) Contempla donaciones y financiación reembolsable a candidatos actuales y potenciales a entrar en la UE. } \\
\hline \multicolumn{4}{|c|}{$\begin{array}{l}\text { (7) El Reglamento del Consejo } 1311 / 2013 \text { por el que se aprueba el MPF } 2014-2020 \text { contempla además, entre los instrumentos de flexibilidad, una } \\
\text { reserva de ayuda de emergencia de carácter interno y externo, con la movilización de hasta } 280 \text { millones de euros anuales a precios de } 2011 \text {-equi- } \\
\text { valentes a } 2.209 \text { millones de euros para el total del periodo } 2014-2020 \text { a precios corrientes-. }\end{array}$} \\
\hline Fuente: Comisión Europea y elaboración propia. & & & \\
\hline
\end{tabular}




\section{Jaime Alcaide Arranz}
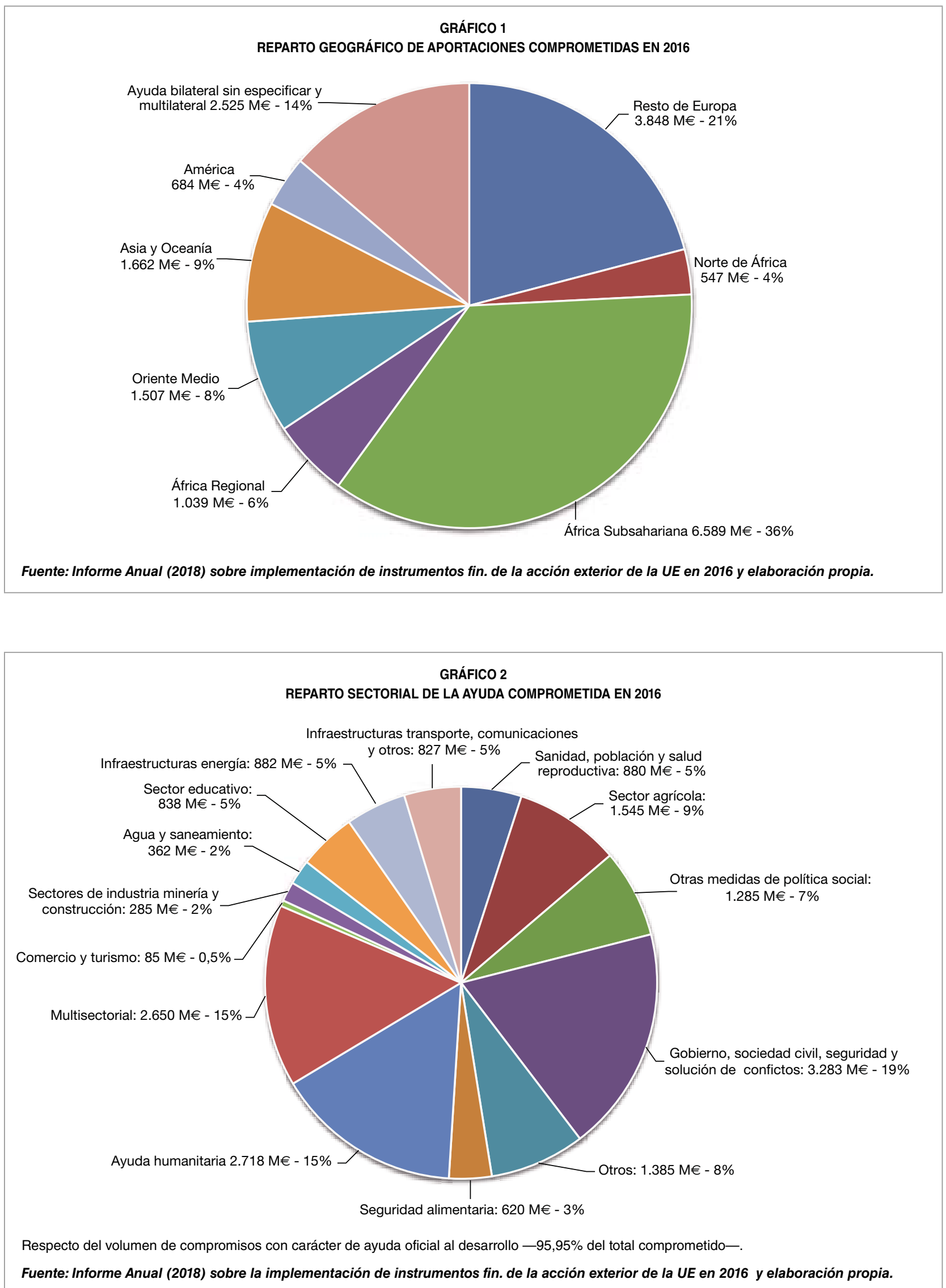
INSTRUMENTOS Y FACILIDADES FINANCIERAS DE LA ACCIÓN EXTERIOR...

CUADRO 2

PRINCIPALES INSTRUMENTOS FINANCIEROS DE LA ACCIÓN EXTERIOR DE LA UE-MPF 2014-2020

\begin{tabular}{|c|c|c|c|c|c|c|}
\hline Principales instrumentos & Zona geográfica & $\begin{array}{l}\text { Dotación } \\
\text { mill. euros }\end{array}$ & Media anual & Año 2016 & $\begin{array}{l}\% \text { total } \\
2014-20\end{array}$ & $\begin{array}{c}\% \text { año } \\
2016\end{array}$ \\
\hline $\begin{array}{l}\text { Fondo Europeo de Desarrollo } \\
\text { Sostenible (FED-EDF) }\end{array}$ & África, Caribe, Pacífico & 30.506 & 4.358 & 6.927 & 31,5 & 37,7 \\
\hline $\begin{array}{l}\text { Instrumento de Cooperación al } \\
\text { Desarrollo (ICD-DCl) }\end{array}$ & $\begin{array}{c}\text { Asia, Oriente M., América } \\
\text { Latina, Sudáfrica }\end{array}$ & 19.662 & 2.809 & 2.705 & 20,3 & 14,7 \\
\hline $\begin{array}{l}\text { Instrumento Europeo de Vecindad } \\
\text { (IEV-ENI) }\end{array}$ & Vecindad Este y Sur & 15.433 & 2.205 & 3.361 & 15,9 & 18,3 \\
\hline Instrumento Preadhesión (IPA) & Candidatos a la adhesión & 11.699 & 1.671 & 2.563 & 12,1 & 13,9 \\
\hline $\begin{array}{l}\text { Total cuatro principales } \\
\text { instrumentos geográficos }\end{array}$ & & 77.300 & 11.043 & 15.556 & 79,9 & 84,6 \\
\hline $\begin{array}{l}\text { Total Acción Exterior } \\
\text { UE MPF 2014-2020 }\end{array}$ & & 96.768 & 13.824 & 18.398 & 100,0 & 100,0 \\
\hline
\end{tabular}

tres años completos disponibles (2014-2016), el promedio de ayuda externa comprometido es de 14.457 millones de euros ${ }^{7}$, con un importe desembolsado medio de 12.047 millones. La senda creciente de los datos anuales responde al efecto de la evolución de precios y al desfase existente en el ciclo de programación y aprobación de los proyectos financiados.

El Gráfico 1 muestra el reparto geográfico de recursos comprometidos - con datos del último ejercicio disponible-, destacando la región de África Subsahariana — sin incluir los compromisos de carácter regional hacia el continente africano- y el conjunto de países europeos no comunitarios (Vecindad Este y países candidatos).

En cuanto al reparto sectorial (Gráfico 2) -y excluyendo las medidas de carácter multisectorial-, destacan los capítulos de ayuda humanitaria; las medidas de carácter gubernamental, de impulso de la sociedad civil, seguridad y solución de conflictos; otras medidas de política social; actuaciones ligadas al sector de la sanidad, población y salud reproductiva; seguidas de los sectores de infraestructuras

7 Con un 93,5 por 100 con carácter de Ayuda Oficial al Desarrollo (AOD). de transporte y comunicaciones e infraestructuras energéticas; sector educativo; gestión de agua y saneamiento; seguidas finalmente de actuaciones en otros sectores económicos y productivos.

De forma agregada, los instrumentos geográficos ocupan un lugar relevante, suponiendo en torno al 80 por 100 del total de recursos (Cuadro 2). EI FED es el principal instrumento -con el 31,5 por 100 del volumen total en el MFP actual-, dirigido al grupo ACP con el que la UE articula sus relaciones en la actualidad a través del Acuerdo Cotonú - firmado en el año 2000 por un periodo de vigencia de 20 años que expira en febrero de $2020^{8}$ - En segundo lugar se sitúa el Instrumento de Cooperación al Desarrollo (ICD) — con el 20,3 por 100- (dirigido a las regiones de Asia, Oriente Medio, América Latina y Sudáfrica), que cuenta asimismo con un bloque de programas temáticos (Cuadro 1). El Instrumento Europeo de Vecindad (IEV) supone un 16 por 100 del total, destinado a las regiones de Vecindad que tienen un carácter prioritario e importancia $\square$

8 El pasado 22 de junio de 2018 el Consejo aprobó el mandato negociador a favor de la Comisión para la negociación de un nuevo acuerdo revisado con los países ACP. 
creciente dada su posición estratégica como fronteras exteriores de la UE. Finalmente, los recursos del Instrumento Preadhesión (IPA) -destinados a los países candidatos- representan el 12,1 por 100 del total. La media anual del conjunto de estos cuatro instrumentos alcanza los 13.855 millones de euros. Por su parte, en 2016 el volumen de recursos comprometidos por estos cuatro instrumentos se situó en 18.398 millones de euros o un 85 por $100 \mathrm{del}$ total (Cuadro 2), con un peso especialmente relevante de las regiones de África y Vecindad.

\section{Programación y gestión de los principales instrumentos y facilidades}

Los principales instrumentos financieros de la acción exterior cuentan con una planificación plurianual y una programación anual, planteadas como resultado de las prioridades y orientaciones estratégicas del Consejo y de la identificación de acciones de interés por parte de la Comisión Europea, el Servicio Europeo de Acción Exterior (SEAE) y las Delegaciones de la $U^{9}{ }^{9}$ (DUE). A tal efecto se desarrollan planes indicativos plurianuales de carácter nacional y regional en el ámbito de los diferentes instrumentos ${ }^{10}$ con los objetivos y sectores de actuación prioritaria ${ }^{11}$, desarrollados posteriormente a través de Programas de Acción Anual

\footnotetext{
9 Con una estrecha relación con las embajadas de los Estados miembros, además de con los países beneficiarios y otros actores de interés.

10 PIN, PIR o PIP, acrónimos de sus diferentes denominaciones. Los planes plurianuales pueden ser modificados como resultados del proceso de evaluación a medio plazo (o mid-term review). Los países graduados — habiendo salido de status de bajos ingresos - no cuentan con planes indicativos a nivel nacional.

11 Además de los recursos previstos en los planes indicativos nacionales plurianuales, los países también pueden recibir apoyo a través de los programas indicativos regionales y temáticos, del Programa Panafricano - de apoyo a la alianza estratégica entre la UE y África一, en su caso, y a través de las facilidades de blending.
}

(PAA), que pueden ser complementados con la presentación de propuestas individuales de actuación adicional. La aprobación de las programación y medidas propuestas tiene lugar en los comités de cada instrumento ${ }^{12}$, presididos por la Comisión y en los que participan los Estados miembros.

Dado el elevado volumen de recursos de la acción exterior, la modalidad tradicional de gestión directa — por parte de la Comisión, agencias y delegaciones de la UE- ha experimentado una progresiva pérdida de peso dando paso un creciente recurso a la gestión indirecta a través de la administración del país beneficiario (vía apoyo presupuestario o contribuciones a instituciones nacionales), de agencias y organismos internacionales (como agencias de Naciones Unidas, entidades del Grupo del Banco Mundial, organismos de integración regional...) o a través de instituciones europeas de desarrollo (bilaterales o multilaterales) acreditadas ante la Comisión Europea ${ }^{13}$.

Entre las entidades europeas bilaterales con un papel destacado en el desarrollo de proyectos bajo gestión delegada ${ }^{14}$ se encuentran la Agencia Francesa de Desarrollo (AFD), el banco de desarrollo alemán (KfW), la agencia de cooperación alemana (GIZ), la Agencia Española de Cooperación Internacional para el Desarrollo (AECID), la Fundación Internacional y para Iberoamérica de Administración y Políticas Públicas (FIIAPP), la cooperación belga Enabel o la danesa DANIDA.

\footnotetext{
12 Existiendo adicionalmente comités operativos para iniciativas, facilidades financieras o fondos específicos.

13 Tras un proceso de acreditación de sus sistemas internos les permite acceder a la gestión y ejecución delegada de fondos comunitarios, siguiendo sus propios procedimientos de licitación y contratación. En el caso de España, se cuenta con tres instituciones acreditadas - FIIAPP, AECID y COFIDES-.

14 Mediante contratos de Cooperación Delegada (CD) y contratos de subvención - con contribuciones directas sin licitación-. Adicionalmente, la gestión delegada incluiría la gestión de recursos procedentes de facilidades de blending.
} 
Los proyectos que reciben financiación comunitaria pueden presentar múltiples modalidades de ejecución: i) licitaciones de suministros, servicios y obras, y convocatorias de propuestas para la concesión de subvenciones -ya sean desarrolladas por parte de la Comisión o de entidades bajo gestión indirecta-; ii) subvención directa sin licitación - por motivos justificados de necesidad o urgencia-; iii) apoyo presupuestario al país beneficiario ${ }^{15}$ - pudiendo restringirse a un determinado sector- en base al cumplimiento de determinados criterios $^{16}$; iv) contribuciones a fondos fiduciarios $(\mathrm{FF})^{17}$ —creados para dar una respuesta rápida a situaciones de crisis o especial necesidad $^{18}$-; v) contribuciones a proyectos de blending o financiación combinada.

Dado su carácter extrapresupuestario, el FED cuenta con estados financieros independientes que permiten obtener mayor información respecto del reparto en la gestión desarrollada — directa e indirecta- como referencia orientativa. La gestión directa de los recursos del fondo representa una media del 33 por $100^{19}$ — con datos de los tres últimos años publicados-, mientras que la gestión indirecta supone el 67 por 100 restante $^{20}$.

15 El apoyo presupuestario supuso una media del 20 por 100 de la ayuda comprometida a través de los cuatro principales instrumentos entre 2014 y 2016 ( 25 por 100 en el FED), elevándose hasta el 21 por 100 en 2016 (29 por 100 en el FED).

16 Con desembolsos progresivos en función del grado de ejecución. El apoyo presupuestario puede dar lugar a procesos de contratación -licitaciones y convocatorias de propuestas - por parte de las autoridades del país y a licitaciones de asistencias técnicas por parte de la Comisión.

17 Con gestión fiduciaria de la Comisión, pudiendo recibir aportaciones adicionales de los Estados miembros y de otros donantes. Destaca posteriormente el uso de la gestión delegada en su ejecución.

18 FF UE de Emergencia para África (EUETF) para hacer frente a las causas profundas de la migración irregular y desplazamiento de personas en África; FF de la UE en respuesta a la crisis en Siria (Fondo Mamad) o el FF para Colombia para apoyar la reconstrucción y el tejido económico y social en zonas rurales tras el proceso de paz en el país.

${ }_{19}$ Incluyendo contribuciones a FF que posteriormente pueden ser objeto de gestión indirecta.

20 Con 25 puntos porcentuales destinados a apoyo presupuestario, dirigiéndose el resto a cooperación delegada, subvenciones y, en menor medida pero de forma creciente, hacia las facilidades de blending.

\subsection{Blending}

La modalidad de blending para la financiación de proyectos de inversión consiste en la combinación de un componente de donación procedente de fondos comunitarios con un componente de financiación reembolsable o de participación en el capital aportado por las instituciones financieras participantes en la operación ${ }^{21}$.

El uso de esta modalidad comienza en el año 2007 como una iniciativa novedosa inicialmente dirigida a cofinanciar proyectos de inversión en infraestructuras en África ${ }^{22}$, extendiéndose progresivamente hacia el resto de regiones a lo largo del periodo plurianual 2007-2013 con la creación de facilidades regionales ${ }^{23}$ (Cuadro 3) para la gestión de las contribuciones procedentes de los correspondientes instrumentos geográficos. Los fondos se destinan a la cofinanciación de proyectos de inversión en los sectores de transporte, energía sostenible, agua y saneamiento, tecnologías de la información, agricultura o medio ambiente ${ }^{24}$.

Las facilidades de blending cuentan con comités operativos asistidos por grupos de análisis técnico (TAM, Technical Analysis $\square$

21 Los beneficiarios pueden ser el sector público o el sector privado local.

22 A través del FF Infraestructuras UE-África (UE-África ITF), gestionado por el $\mathrm{BEl}$, antecesor de la Facilidad de Inversión para África (AIF) de 2015.

23 En 2008 se crea la Facilidad de Inversiones para Vecindad (NIF), en 2009 surge la Plataforma de Inversiones para los Balcanes Occidentales (WBIF) - como iniciativa conjunta de la Comisión el BEI, el BERD y varios donantes bilaterales (con la incorporación de KfW en 2017 y la solicitud de la AFD para incorporarse en 2018)—, en 2010 se crean las Facilidades de Inversión para Latinoamérica y Asia Central (LAIF y IFCA) y en 2012 nacen las Facilidades de Inversión para Pacífico, Caribe y Asia (IFC, CIF y AIF). En el MFP actual se crea la Facilidad temática. Las facilidades se agrupan en marcos de blending relativos a los correspondientes instrumentos financieros, en línea con las recomendaciones de la Plataforma de la UE para el blending en la cooperación exterior (EUBEC) creada en 2012.

24 El 65 por 100 de las operaciones corresponden a proyectos de escala nacional o subnacional, mientras que en el 35 por 100 se trata de proyectos dirigidos a dos o más países (65 por 100 de ellas en el caso de África Subsahariana). 
CUADRO 3

FACILIDADES DE BLENDING EN 2018

\begin{tabular}{|c|c|c|c|}
\hline Marco de blending & Facilidades de inversión & Marco de blending & Facilidades de inversión \\
\hline \multirow{3}{*}{ Marco de Blending del FED } & $\begin{array}{l}\text { Plataforma de Inversión } \\
\text { para África (AIP) }\end{array}$ & \multirow{3}{*}{$\begin{array}{l}\text { Marco de Blending } \\
\text { del ICD }\end{array}$} & $\begin{array}{c}\text { Facidad de Inversión para América } \\
\text { Latina (LAIF) }\end{array}$ \\
\hline & $\begin{array}{l}\text { Facilidad de Inversión } \\
\text { para el Caribe (CIF) }\end{array}$ & & $\begin{array}{l}\text { Facilidad de Inversión para Asia } \\
\text { (AsIF) }\end{array}$ \\
\hline & $\begin{array}{l}\text { Facilidad de Inversión } \\
\text { para el Pacífico (IFP) }\end{array}$ & & $\begin{array}{l}\text { Faciliad de Inversión para Asia } \\
\text { Central (IFCA) }\end{array}$ \\
\hline Marco de Blending de Vecindad & $\begin{array}{l}\text { Platafora de Inversión } \\
\text { de Vecindad (NIP) }\end{array}$ & $\begin{array}{l}\text { Marco de Blending de } \\
\text { Balcanes Occidentales }\end{array}$ & $\begin{array}{l}\text { Western Balkans Investment } \\
\text { Framework (WBIF) }\end{array}$ \\
\hline
\end{tabular}

Meeting). La entidad acreditada que lidera el proyecto - debiendo contar este con el respaldo de la DUE correspondiente- se encarga del diseño de la operación y de la presentación de la solicitud formal con el asesoramiento de la Comisión (DEVCO C3, Unidad de Instrumentos Financieros). Las propuestas son presentadas en el grupo técnico o TAM, en el que participan todas las entidades acreditadas, como paso previo a su aprobación por parte de los EEMM en el correspondiente comité operativo, dando paso a la negociación y firma del contrato con la Comisión ${ }^{25}$.

Entre las instituciones que pueden liderar este tipo de operaciones - recibiendo donaciones comunitarias - se encuentran las entidades financieras de desarrollo de los Estados miembros acreditadas ante la Comisión para proyectos de blending ${ }^{26}$, instituciones financieras multilaterales europeas — caso del Banco Europeo de Inversiones (BEI) y del Banco Europeo de Reconstrucción y Desarrollo (BERD)—, así como instituciones financieras

\footnotetext{
25 Con el apoyo de las DUE.

26 Entre las entidades acreditadas para blending se encuentran la Agencia Española de Cooperación Internacional para el Desarrollo (AECID) desde 2011 — con financiación procedente del Fondo para la Promoción del Desarrollo (FONPRODE), habiendo impulsado varios proyectos de blending - y la Compañía Española de Financiación del Desarrollo (COFIDES) desde 2016 - con financiación procedente de sus recursos propios y la posibilidad de hacer uso de la línea FIEM Facilidades UE, con la firma del primer proyecto de blending en 2018-.
}

de desarrollo regionales en sus respectivas regiones - caso del Banco Africano de Desarrollo (BAfD) o del Banco Interamericano de DesarroIlo (BID) - . La participación de otro tipo de entidades que lideran operaciones de blending está restringida por la legislación comunitaria en base al principio de preferencia comunitaria, con la posibilidad de aplicar excepciones ${ }^{27}$.

De acuerdo con los datos del Informe de Evaluación del blending ${ }^{28}$, entre las entidades líderes destacan de manera particular el BEI, el BERD, la AFD y KfW, seguidas del BAfD. Los proyectos liderados por las cuatro primeras representan el 93 por 100 del número total y el 92 por 100 de las contribuciones comunitarias (en torno al 30 por 100 en el caso del BEl y al 20 por 100 en las tres restantes). En este sentido, las principales instituciones financieras muestran una significativa capacidad de liderazgo y captación de recursos, junto a su elevada capacidad de concesión de financiación y de identificación y origen de proyectos.

El Gráfico 3 muestra el reparto de los recursos comunitarios destinados a proyectos de $\triangleright$

\footnotetext{
27 Cuando la entidad en cuestión cuente con conocimientos específicos frente a necesidades locales, especial capacidad, expertise y know-how respecto de las operaciones y sectores o elevada capacidad de apalancamiento de recursos.

28 Fuente: Figura 7, página 9; Anexo B1, Informe de Evaluación del blending (CE, 2016).
} 


\section{INSTRUMENTOS Y FACILIDADES FINANCIERAS DE LA ACCIÓN EXTERIOR...}

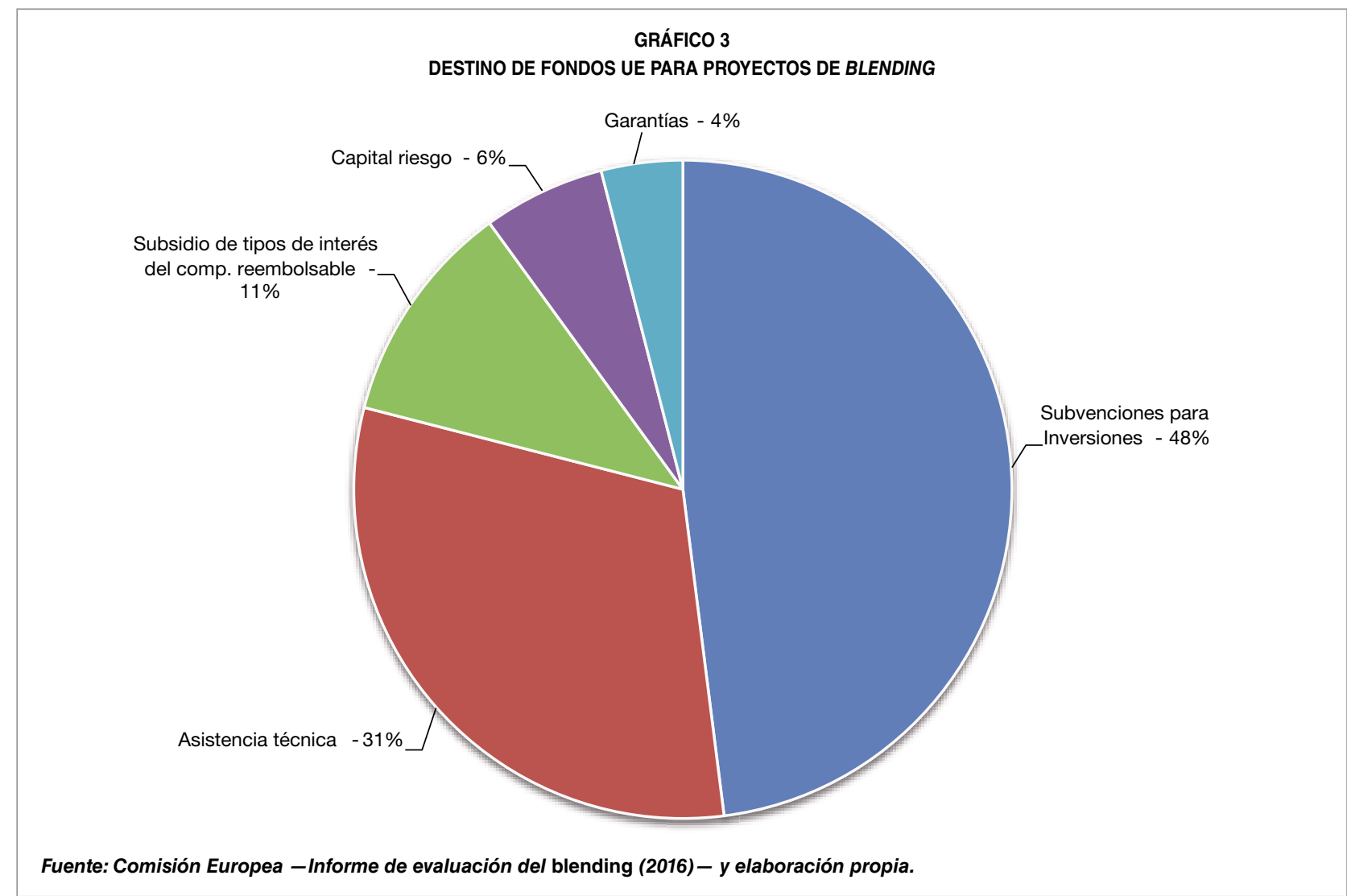

\section{GRÁFICO 4}

REPARTO DE ASIGNACIONES INDICATIVAS - BLENDING 2007-2020

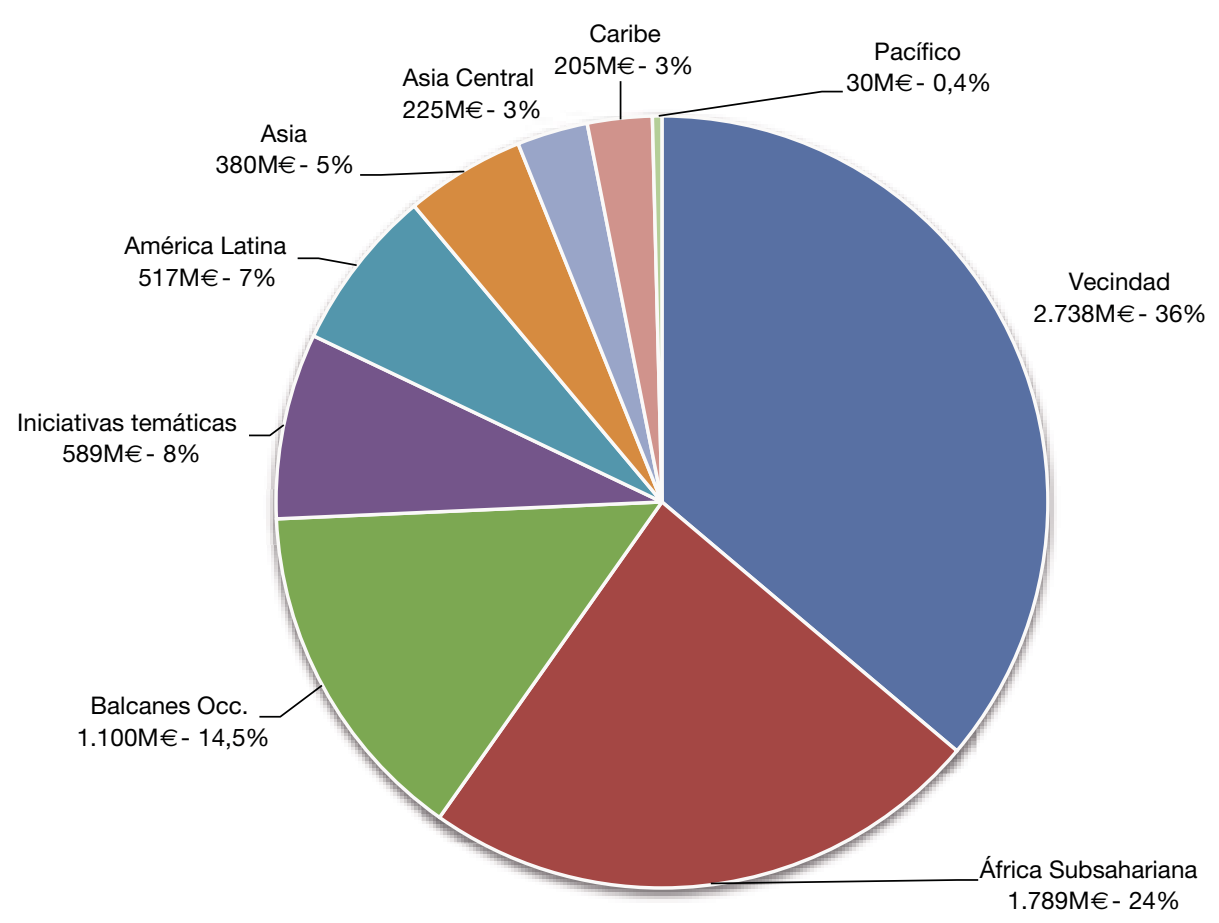

Fuente: Comisión Europea (DEVCO) - sobres acumulados 2007-2013 y asignaciones indicativas 2014-2020- y elaboración propia. 
financiación combinada, destacando las subvenciones para inversiones y la financiación de asistencias técnicas para la preparación y supervisión de proyectos ${ }^{29}$. Les siguen, en menor medida, los subsidios al tipo de interés de la financiación reembolsable, la contribución a fondos de capital riesgo ${ }^{30}$ (habitualmente mediante la subscripción de acciones del tramo junior o subordinado con exposición a primeras pérdidas) y las garantías -con o sin remuneración-, con un cobertura parcial de primeras pérdidas.

En un contexto de múltiples y elevadas necesidades con unos recursos disponibles limitados, la cofinanciación comunitaria permite mitigar los riesgos teniendo un efecto catalizador con la movilización de financiación reembolsable e inversión adicional del sector privado, facilitando el desarrollo de proyectos de envergadura y valor añadido en países en desarrollo.

Con datos acumulados hasta 2016, las donaciones comunitarias para proyectos de financiación combinada han superado los $3.400 \mathrm{mi}-$ llones de euros, destinados a 380 proyectos con la movilización de $\mathbf{2 6 . 0 0 0 ~ m i l l o n e s ~ d e ~ f i n a n - ~}$ ciación reembolsable y una inversión total estimada por la Comisión de 57.000 millones de euros. De este modo, la Comisión calcula que esta modalidad ha logrado alcanzar un efecto palanca de 17 euros por cada euro comprometido. La cifra de donaciones acumuladas prevista para el año $2020^{31}$ es superior a los 7.500 millones de euros. El Gráfico 4 muestra el reparto de las asignaciones previstas por zonas geográficas, destacando de manera particular las regiones de Vecindad y África, seguidas de

\footnotetext{
29 La financiación de asistencias técnicas se encuentra presente de forma transversal en un 40 por 100 de los proyectos.

30 Con diferente tipo de acciones por tramos, en el grado de exposición al riesgo y con secuencia de retornos en cascada.

31 A partir de los sobre acumulados para 2007-2014 y las asignaciones indicativas para el MFP 2014-2020.
}

los Balcanes Occidentales, frente a porcentajes moderados en los caso de América Latina y Asia.

Las donaciones para blending han mostrado un notable avance en términos anuales ${ }^{32}$, aproximándose al entorno del 10 por 100 del volumen desembolsado por los cuatro principales instrumentos geográficos en los últimos ejercicios del MFP actual, con la voluntad de la Comisión de continuar con un compromiso reforzado a favor de esta modalidad.

\subsection{El Plan Europeo de Inversiones Exteriores}

Con el objetivo de profundizar en mecanismos de cooperación financiera que estimulen la participación del sector privado, la Comisión Europea lanzó, en septiembre de 2017, el Plan Europeo de Inversiones Exteriores (PEIE), para impulsar el desarrollo de infraestructuras en los países beneficiarios de la acción exterior europea $^{33}$ - estando inicialmente enfocado en las regiones de África y Vecindad- a través de actuaciones que contribuyan a mejorar el atractivo de proyectos, así como el clima de negocios e inversiones.

EI PEIE consta de tres pilares -la creación de un fondo de garantía, un marco de asistencia técnica y un marco de mejora del clima de inversiones- para lograr un efecto catalizador que promueva una mayor involucración de inversores privados en proyectos que favorezcan la creación de empleo, el crecimiento $\triangleright$

\footnotetext{
32 De 719 millones de euros en 2015, 779 millones de euros en 2016, según los últimos informes anuales publicados, y superiores a los 1.200 millones de euros en 2017, con datos preliminares, según la información publicada en el Informe Operativo de 2017 del Fondo Europeo de Desarrollo Sostenible (CE, 2018).

33 Como continuación de la estrategia desarrollada a través del Plan Europeo de Inversiones de la Comisión lanzado en 2014 por el presidente de la CE, conocido como el Plan Juncker.
} 
inclusivo, el desarrollo sostenible, así como hacer frente a las causas profundas de la inmigración irregular —en un contexto de aumento de crisis migratorias y población desplazada-.

Como primer pilar del PEIE se crea el Fondo Europeo de Garantía Sostenible (FEDS), que incluye un fondo de garantía dotado con 1.500 millones de euros ${ }^{34}$, para facilitar la movilización de financiación ${ }^{35}$ a través de la concesión de garantías ${ }^{36}$ como vía de mitigación de riesgos y de apalancamiento de capital adicional a favor de proyectos de inversión. Además, las medidas de asistencia técnica y de mejora del clima de negocios e inversión ${ }^{37}$ - segundo y tercer pilar del PEIE- tienen como objetivo acompañar el impulso de la cooperación financiera para facilitar el éxito de la estrategia.

El nuevo reglamento de FEDS establece que este estará compuesto por dos plataformas de inversión para cada una de las regiones -África y Vecindad en la actualidad — basadas en las existentes facilidades regionales para financiación combinada y sus correspondientes comités - renombrados como plataformas-, combinando las operaciones de blending con las del fondo de garantía. Asimismo, se ha creado un comité técnico de análisis de garantías (denominado G-TAG, por sus siglas en inglés) para la evaluación del riesgo y valoración de las operaciones propuestas ${ }^{38}$.

\footnotetext{
34750 millones de euros de contribuciones comunitarias - 400 millones de euros para la región de África procedentes del FED y 350 millones de euros para la región de Vecindad procedentes del presupuesto comunitario (100 millones procedentes del ENI y 250 del margen para contingencias en el MFP actual)-, con otros 750 millones de euros como pasivo contingente a ser cubierto por el presupuesto de la UE.

35 Financiación reembolsable, instrumentos de capital y cuasicapital, garantías y contragarantías, etcétera.

36 Garantías incondicionales, irrevocables a primera demanda. Con una cuota mínima del 28 por 100 para acciones de lucha contra el cambio climático, energías renovables y sostenibilidad.

37 Diálogo político, apoyo de reformas estructurales, mejora de marcos regulatorios...

38 Con un papel destacado del BEI, en cooperación con la Comisión, y la participación de representantes de otras entidades financieras europeas.
}

La gestión del fondo contará además con el asesoramiento de un consejo o comité estratégico, que se reunirá al menos dos veces al año ${ }^{39}$, estableciendo las orientaciones y principios de actuación y supervisando la gestión del fondo.

EI FEDS dispone de una ventanilla única o one-stop-shop para la presentación de propuestas por parte de instituciones financieras europeas - bilaterales o multilaterales - con la novedad de poder recibir propuestas por parte del sector privado, que serán sometidas al Secretariado del FEDS y al G-TAG, como paso previo a ser elevadas a los comités operativos regionales. Finalmente, tras contar con la opinión favorable de estos, la Comisión se encarga de la negociación y firma de los acuerdos con las instituciones financieras.

Se han establecido cinco sectores o ventanas de inversión sobre los que presentar propuestas de inversión (o PIPs, por sus siglas en inglés): i) energía sostenible y conectividad, ii) financiación a microempresas y pequeñas y medianas empresas, iii) agricultura sostenible, empresarios rurales e industria agroalimentaria, iv) ciudades sostenibles y v) sector digital para el desarrollo, habiendo tenido lugar la presentación de las primeras propuestas en la primera parte de 2018.

El pasado 10 de julio de 2018 tuvo lugar la reunión de los comités operativos del FEDS que dieron luz verde a la aprobación del paquete de garantías destinado a los 12 primeros programas ${ }^{40}$ de proyectos de inversión $\triangleright$

\footnotetext{
39 Formado por representantes de la CE y del Gabinete de la Alta Representante, de los Estados miembros y del BEl.

40 Entre los doce primeros programas se encuentran dos con participación española. El primero - InclusiFI—, en el ámbito de la inclusión financiera, cuenta con la participación conjunta de AECID y la italiana CDP, complementada con la presencia de COFIDES. El segundo - RECIDEestá enfocado en ámbito de ciudades sostenibles y estará liderado por AECID.
} 
pública y privada, en África y Vecindad, por un valor aproximado de 800 millones de euros ${ }^{41}$.

Conjugando los recursos del fondo de garantía con las contribuciones disponibles en las facilidades de blending ${ }^{42}$-AfIP y NIF-, la Comisión calcula que se podrían movilizar inversiones por un valor de 44.000 millones de euros, con un efecto palanca equivalente de 11 euros por cada euro invertido, lo que permitiría obtener avances significativos en los países beneficiarios desde el punto de vista económico y social.

\subsection{Participación de empresas}

Los proyectos financiados por la acción exterior de la UE generan, por otra parte, procesos de contratación, suponiendo un aprovechamiento comercial para distintos tipo de operadores y empresas ${ }^{43}$ con un bajo riesgo de cobro. En cuanto al tipo de operaciones, los proyectos de capacitación, asistencia técnica o formación pueden suponer una fuente de actividad en el terreno de la consultoría, con la contratación de servicios, asistencias y estudios - y en menor medida suministros-, atendiendo también a la posibilidad de dar entrada a entidades locales de países beneficiaros. En el caso de contratos de subvención a favor de instituciones de desarrollo, estos pueden ser ejecutados en cierto grado por estas, con sus propios medios, con un peso minoritario o segmentado de

\footnotetext{
$41 \mathrm{Y}$ en torno a 80 millones de euros adicionales para asistencia técnica.

42 Por un valor superior a los 2.600 millones de euros, de acuerdo con datos de la Comisión. Además, el fondo y las plataformas de inversión están abiertos a la posibilidad de recibir contribuciones adicionales por parte de otros Estados miembros, así como de otros donantes -financiación, garantías y asistencias técnicas-, como ha sido el caso de la Fundación de Bill y Melinda Gates (BMGF) por valor de 62 millones de dólares (53 millones de euros).

$43 \mathrm{Y}$ organismos de la sociedad civil (OSC) a través de la convocatoria de propuestas en diferentes tipos de actividades de carácter social o educativo.
}

subcontrataciones (expertos, estudios...) y suministros. En el caso de proyectos de infraestructuras, obras y estudios técnicos, las licitaciones pueden implicar oportunidades de negocio con un importe medio superior en el valor de las contrataciones.

Respecto de la entidad contratante, pueden existir procesos de licitación y convocatorias realizadas de forma directa por la Comisión -en proyectos de gestión directa- o por parte de terceros -en el caso de gestión indirecta-, como instituciones financieras de desarrollo multilaterales o entidades financieras y agencias bilaterales de desarrollo de los EEMM. En proyectos bajo gestión delegada, la entidad acreditada que lidera la operación puede aplicar su propia normativa de contratación ${ }^{44}$. Así puede existir diferente grado y capacidad de aprovechamiento comercial según el tipo de proyecto, la entidad contratante y sus procedimientos, lo que podría redundar en beneficio de aquellas empresas — de la misma nacionalidad o no que la entidad licitante- más familiarizadas o habituadas a sus procesos, canales de difusión o incluso idiomas utilizados en estos.

El Cuadro 4 recoge una tabla con los enlaces a las páginas de anuncios de licitación y oportunidades de negocio de diferentes instituciones, incluyendo los datos divulgados por la DG de Desarrollo y Cooperación Internacional de la Comisión y los anuncios publicados ${ }^{45}$ en el Diario Oficial de la UE ${ }^{46}$.

\footnotetext{
44 Además de poder delegar la contratación en otra entidad internacional participante en la operación o en una entidad pública del país beneficiario.

45 Publicación de contrataciones por encima de los umbrales recogidos en la Guía Práctica de procedimientos contractuales para la acción exterior de la UE (PRAG 2016): https://ec.europa.eu/europeaid/ funding/about-funding-and-procedures/procedures-and-practicalguide-prag_en

46 Cuñat et al. (2012) estiman que se incluye información de en torno al 50 por 100 de los contratos adjudicados, con un 67 por 100 de ellos contratado por operadores comunitarios en el periodo de estudio $(9,7$ por 100 de estos españoles).
} 
CUADRO 4

ANUNCIOS DE LICITACIÓN, CONVOCATORIAS DE PROPUESTASY OPORTUNIDADES DE NEGOCIO DE DIFERENTES INSTITUCIONES

\begin{tabular}{|c|c|}
\hline $\begin{array}{l}\text { Lista no exhaustiva de páginas webs de diferentes } \\
\text { instituciones }\end{array}$ & Enlaces \\
\hline $\begin{array}{l}\text { Anuncios DG Desarrollo y Cooperación Internacional } \\
\text { (DEVCO) }\end{array}$ & $\begin{array}{l}\text { https://webgate.ec.europa.eu/europeaid/online-services/index. } \\
\text { cfm?ADSSChck=1535355474325\&do=publi.welcome }\end{array}$ \\
\hline $\begin{array}{l}\text { Beneficiarios de fondos de la acción exterior de la UE } \\
\text { (DEVCO) }\end{array}$ & http://ec.europa.eu/europeaid/work/funding/beneficiaries \\
\hline TED (Tenders Electronic Daily)-Diario Oficial UE & http://ted.europa.eu/TED/main/HomePage.do \\
\hline $\begin{array}{l}\text { Ventanilla única del Fondo Europeo de Desarrollo } \\
\text { Sostenible }\end{array}$ & $\begin{array}{l}\text { https://ec.europa.eu/commission/eu-external-investment-plan/ } \\
\text { how-you-can-engage-external-investment-plan-one-stop-shop_en }\end{array}$ \\
\hline Licitaciones COFIDES & https://www.cofides.es/contratos-en-fase-de-licitacion/ \\
\hline Licitaciones AECID & http://www.aecid.es/ES/la-aecid/anuncios/licitaciones \\
\hline Licitaciones FIIAPP & http://www.aecid.es/ES/la-aecid/anuncios/licitaciones \\
\hline Licitaciones Agencia Francesa de Desarrollo & https://afd.dgmarket.com/tenders/brandedNoticeList.do \\
\hline Licitaciones KfW & http://vergabe.kfw.de/NetServer/ \\
\hline Licitaciones GIZ & https://www.giz.de/en/workingwithgiz/bidding_procurement.html \\
\hline Licitaciones Cassa Depositi e Prestiti & $\begin{array}{l}\text { https://portaleacquisti.cdp.it/esop/toolkit/opportunity/opportunityList. } \\
\text { do?reset=true\&resetstored=true\&oppList=CURRENT }\end{array}$ \\
\hline Licitaciones Banco Europeo de Inversiones & http://www.eib.org/about/procurement/index.htm \\
\hline $\begin{array}{l}\text { Licitaciones Banco Europeo de Reconstrucción y } \\
\text { Desarrollo }\end{array}$ & http://www.ebrd.com/work-with-us/procurement.html \\
\hline Licitaciones Banco Africano de Desarrollo & https://www.afdb.org/en/projects-and-operations/procurement/ \\
\hline Licitaciones Banco Interamericano de Desarrollo & Licitaciones BIAD https://www.iadb.org/en/procurement \\
\hline Servicio ICEX de oportunidades de negocio & $\begin{array}{l}\text { https://www.icex.es/icex/es/navegacion-principal/todos-nuestros-servi- } \\
\text { cios/oportunidades-de-negocio/inicio/index.html }\end{array}$ \\
\hline
\end{tabular}

\section{La actividad extracomunitaria del Banco Europeo de Inversiones (BEI)}

EI BEI nace en 1958 con el objetivo de contribuir al desarrollo regional y a la cohesión económica y social en el proceso de integración comunitario y cuyo capital social está suscrito por los Estados miembros ${ }^{47}$, con una calificación crediticia de AAA, e importante actividad

47 España cuenta con un 9,666 por 100 del capital suscrito/ desembolsado, ocupando la quinta posición, y pasará a ser el cuarto accionista tras la retirada de Reino Unido. En diciembre de 2017 el Consejo aprobó el proceso de retirada progresiva del capital del Banco por parte de Reino Unido, en línea con la primera fase del proceso de salida, si bien Reino Unido ha manifestado la voluntad de seguir manteniendo relación con el Banco, con un marco de relaciones objeto de discusión en la segunda fase de las negociaciones de salida. emisora en los mercados financieros ${ }^{48}$. El 10 por 100 de su actividad se destina a la financiación de proyectos de inversión en países no comunitarios para contribuir a su desarrollo. La actividad crediticia del banco ha mostrado un significativo crecimiento en las últimas décadas. Entre los años 2013 y 2015 tuvo lugar un aumento del capital del 10 por 100 , con un incremento de su inversión crediticia de en torno al 40 por 100.

El BEI cuenta un Mandato Externo (External Lending Mandate o EML) —en la actualidad $D$

48 El Banco tiene un ratio de capital CET-Tier 1 de 28,5 por 100 en 2017 (2,1 puntos porcentuales superior al año anterior) y cuenta además con margen respecto del elevado capital suscrito no desembolsado de en torno a 221.600 millones de euros (frente a los 21.700 millones de euros desembolsados). 
para el periodo 2014-2020, aprobado por el Consejo y el Parlamento Europeo (PE) - que le permite aportar financiación reembolsable destinada a operaciones en países no comunitarios no $\mathrm{ACP}$, con un volumen total previsto

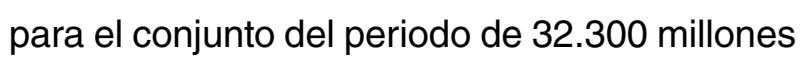
de euros ${ }^{49}$, contando con una cobertura del 65 por $100^{50}$ de los riesgos de tipo político y soberano con cargo a las garantías aportadas por parte del Presupuesto de la UE.

En cuanto a la operativa en los países ACP, la actividad del banco se sustenta en base al Acuerdo Cotonú firmado entre los países ACP y los Estados miembros, con una financiación garantizada de hasta un 75 por 100 por parte de los Estados miembros. El Acuerdo Cotonú supuso la creación de la Facilidad de Inversión para el grupo ACP (FI o IF, por sus siglas en inglés) creada a partir de recursos del FED como un fondo rotativo o revolving —que implica que las amortizaciones que se vayan produciendo se van reinvirtiendo en nuevas operaciones - gestionado por el BEI ${ }^{51}$. Opera desde 2003 con los objetivos de eficiencia y sostenibilidad financiera ${ }^{52}$ con el fin de financiar inversiones del sector privado y el sector público empresarial en los diferentes países, a través de la concesión de deuda junior o subordinada, participación en el capital, instrumentos de cuasicapital y garantías y con la posibilidad de financiar operaciones en moneda local. La IF cuenta con unos recursos procedentes de las aportaciones del 9o $(2000-2007), 10^{\circ}$ (2008-2013) y 11으 FED (2014-2020) con un valor

\footnotetext{
49 Tras el aumento de febrero de 2018 en el marco del mid-term review del Mandato Externo, con un 85,9 por 100 del total destinado a Vecindad Sur, Vecindad Este y candidatos actuales y potenciales - frente al 82 por 100 de los 25.800 millones de euros del Mandato Externo en el periodo 2007-2013- El mandato se estructura en las áreas de Vecindad, Preadhesión y resto de Cooperación al Desarrollo.

5075 por 100 en el caso de países mediterráneos.

51 Reglamento del Consejo (EU) 2015/323, de 2 de marzo de 2015, sobre la regulación financiera aplicable al 11. FED.

52 Reportando al Comité IF que cuenta con la representación de la Comisión y los EEMM.
}

actual total de 3.637 millones de euros para la región ACP y 48,5 millones de euros dirigidos a proyectos en las Regiones y Territorios de Ultramar (RTU). Además, la IF cuenta con un componente de donación para la financiación de asistencia técnica y subsidio del coste financiero por un importe de 634 millones de euros para el grupo ACP y de 5 millones de euros para las RTU. A lo anterior se añaden los recursos comprometidos procedentes del BEI para financiar operaciones fuera de la UE para el periodo 20142020 por valor de 2.500 millones de euros.

Por otra parte, en el año 2013 se aprobó la creación del Impact Financing Envelope (IFE) como un nuevo instrumento separado dentro del IF, con una dotación de 500 millones de euros -alcanzándose en 2016 un acuerdo para aumentar la dotación hasta los 800 millones de euros y convertirse en un fondo rotativo o revolving ${ }^{53}$-, cuyo objetivo es participar en operaciones con un elevado impacto positivo esperado cuyo mayor perfil de riesgo podría dificultar su desarrollo, sin penalizar la sostenibilidad financiera del IF —estando especialmente enfocado en áreas ligadas a sostenibilidad y desafíos ambientales y en cuestiones de migración o necesidades especiales de tipo social, educativo o sanitario-. Este instrumento, puesto en funcionamiento en 2014 , canaliza los recursos a través de financiación a intermediarios, fondos de capital riesgo con impacto social, instrumentos participativos y financiación directa, pudiendo realizarse en moneda local.

El banco cuenta con una actividad crediticia significativa, con un ligero retroceso en la firma de préstamos en los últimos dos años, pasando de un valor de 84,5 millardos de euros en 2015 a 76,4 millardos de euros en 2016 y a $\triangleright$

53 Con el compromiso de tener un especial enfoque hacia cuestiones de migración. 
69,9 millardos de euros en $2017^{54}$. En este último año se han destinado 7.302 millones de eu$\operatorname{ros}^{55}$ a países no comunitarios - lo que supone en torno al 10 por 100 del total-.

En cuanto al reparto geográfico de la nueva financiación concedida en 2017 , un punto porcentual se ha dirigido a préstamos en países candidatos, otro punto a la región de Vecindad Este, tres puntos a Vecindad Sur, dos puntos al grupo ACP y RTU ${ }^{56}$ y tres puntos porcentuales a Asia y América Latina, hasta completar el 10 por 100 en países no comunitarios. La financiación se ha encauzado hacia sectores de infraestructura económica y social (energía, agua, educación, agricultura, transporte...), así como a cuestiones de migración, integración regional y de adaptación y mitigación frente al cambio climático ${ }^{57}$, con algunas de estas áreas incluidas de forma transversal.

Asimismo, en el año 2016 se han puesto en marcha nuevas iniciativas para hacer frente a desafíos específicos. Es el caso de Boost Africa, una iniciativa conjunta del BEl y el BAfD con el objetivo de impulsar la innovación y la iniciativa empresarial en el continente africano con la dinamización de fondos de capital riesgo, incubadoras de negocio y plataformas de emprendimiento para dar soporte a empresas en fase temprana con capacidad de crecimiento y de creación de empleo, a través de financiación, asistencia técnica y asesoramiento. La iniciativa cuenta con una gestión conjunta de ambos bancos y aportaciones iniciales de 50 millones de euros de cada uno, estando abierta a aportaciones de nuevos socios de los sectores público y privado.

\footnotetext{
54 El objetivo del BEl es alcanzar un valor de en torno a 67.000 millones de euros en préstamos firmados en 2018.

55 Con préstamos aprobados por valor de 7.995 millones de euros y una cifra de desembolsos de 6.301 millones de euros en 2017.

56 Con 1.386 millones de euros en el grupo ACP -716 millones de euros a través de la IF y 670 millones procedentes de recursos propios-.

57 Con el objetivo de que la financiación que incluya cuestiones de climate action alcance un 35 por 100 en el año 2020.
}

También en 2016 —en un contexto de crecientes desafíos migratorios y desplazamiento de refugiados - se acordó destinar al menos 500 millones de la Facilidad de Inversiones para ACP para proyectos que incorporen un componente ligado a cuestiones de migración. Ese mismo año, y también como parte de la respuesta a los nuevos desafíos migratorios, se lanzó la Iniciativa de Resiliencia Económica (ERI, por sus siglas en inglés) para la movilización de financiación en apoyo de la capacidad económica de las economías de la región de Vecindad Sur y de los Balcanes Occidentales, invirtiendo en infraestructuras y desarrollo del sector privado, contemplando asistencias técnicas y subsidios que acompañen a la financiación reembolsable, incluyendo la posibilidad de entrada de diferentes donantes bilaterales y multilaterales en la iniciativa. En febrero de 2018 el Consejo y el Parlamento dieron su aprobación —en el marco del proceso de evaluación a medio plazo (mid-term review) del Mandato Externo- para destinar 3.700 millones de euros a favor de la iniciativa ERI, adicionales a los importes contemplados en la actividad del banco para ambas regiones.

Desde el punto de vista acumulado, la cartera de préstamos en vigor en $2017^{58}$ alcanza los 567.900 millones de euros, correspondientes a 6.103 operaciones. De ellos, 62.861,7 millones corresponden a 944 operaciones en países no comunitarios $^{59}$. El Gráfico 5 refleja el reparto de la cartera de préstamos en vigor en países no comunitarios, poniendo de manifiesto el peso relevante del resto de Europa y Vecindad, y el menor peso de las regiones de países ACP o América Latina.

58 Con 797 operaciones en vigor en España por valor de 92.317 millones de euros, siendo el primer país beneficiario.

5911 por 100 del volumen total y 15,4 por 100 de operaciones en vigor. 


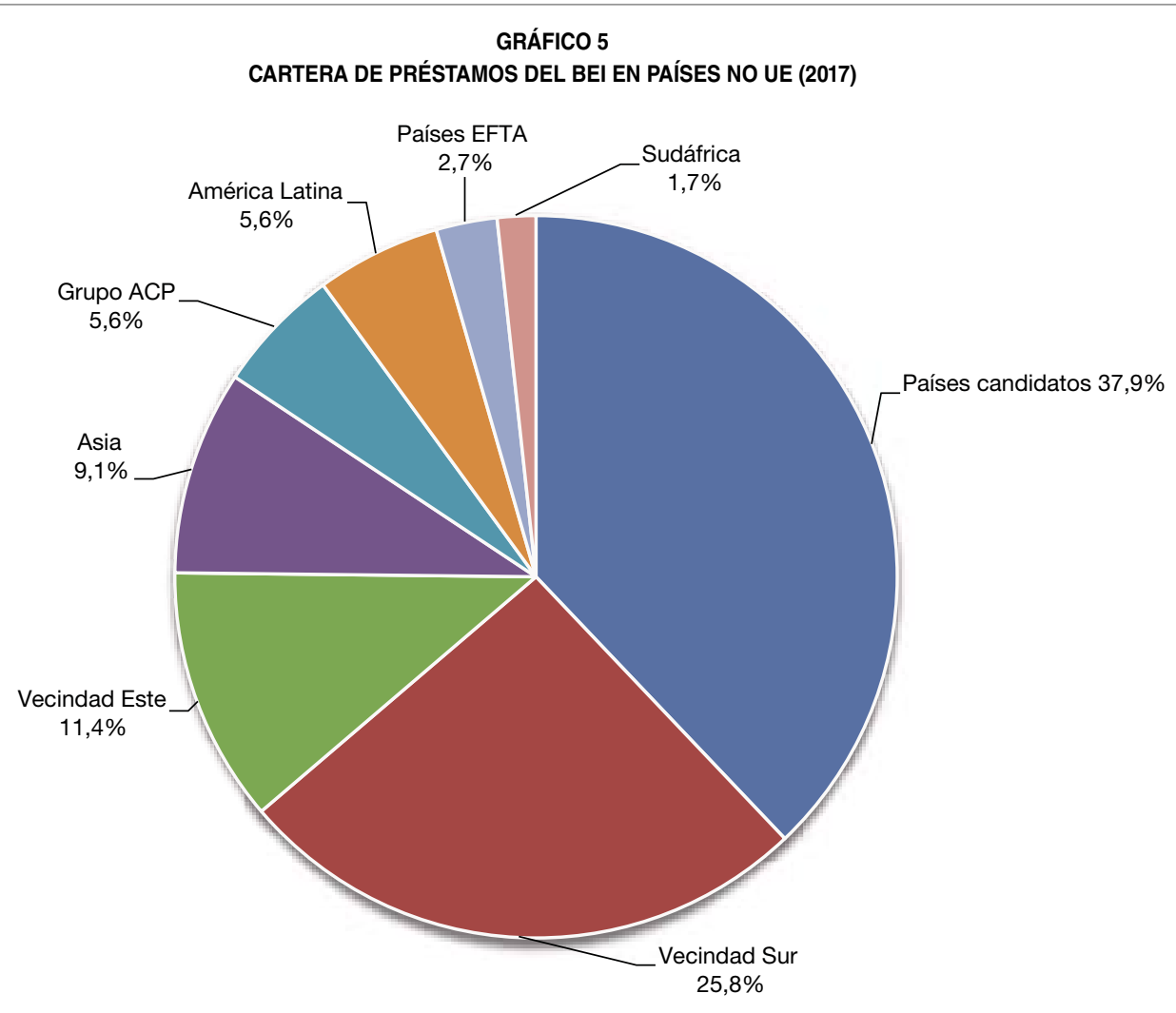

Fuente: Informe Financiero del BEI en 2017 y elaboración propia.

El banco desarrolla su actividad en coordinación con la Comisión y otras instituciones europeas, así como con otras agencias e instituciones financieras de desarrollo ${ }^{60}$. Además, como se ha señalado previamente, el BEI puede liderar proyectos de blending recibiendo donaciones comunitarias para facilitar el desarrollo de estos. Por otra parte, y fruto de la coordinación con otras entidades europeas, en 2013 se lanzó la Mutual Reliance Initiative (MRI) entre el $\mathrm{BEI}$, la KfW, la AFD y la Comisión, que establece que en los proyectos cofinanciados liderados por una de las tres instituciones el resto de ellas se compromete a respetar los estándares y procedimientos de la primera. El banco también ha llegado a alianzas con otras entidades a nivel

60 El BEl también es el administrador fiduciario de diferentes fondos fiduciarios (TF), como el EU-Africa Infrastructure TF — facilidad antecesora de la AIF para la cofinanciación de proyectos de blending en África-, el Neighbouring Investment Facility (NIF) TF o el Fondo Euro-Mediterráneo de Inversión y Asociación (FEMIP) TF. bilateral, como el acuerdo con COFIDES reforzado en marzo de 2018 para la cofinanciación de operaciones -especialmente bajo la modalidad de blending - , con el compromiso del BEI de aportar hasta 200 millones de euros en proyectos liderados por la entidad española.

En un contexto de impulso de la actividad del BEI fuera de la UE también han surgido propuestas relativas a posibles cambios en la estructura del banco. Una de ellas se recogió en el informe de evaluación a medio plazo del mandato externo 2007-2013, liderado por Michel Camdessus (Camdessus et al., 2010), que sugería reforzar la capacidad financiera, la visibilidad y el ámbito de actuación de la Facilidad de Inversión más allá del grupo ACP, planteando la posibilidad de transformar esta en una entidad legal independiente subsidiaria del BEI y orientada a impulsar el desarrollo en terceros países. 
Por su parte, el presidente del BEI planteó, en noviembre de 2017, la propuesta de creación de una entidad subsidiaria del BEI para agrupar la actividad del banco fuera de la UE, a modo de banco europeo de desarrollo ${ }^{61}$, denominada como Banco de la UE para Inversiones Exteriores y Partenariado (EU Bank for External Investment and Partnership, o EUBIP) ${ }^{62}$ — que podría estar abierta a países e instituciones no comunitarias en un contexto de salida de Reino Unido de la UE-. Si bien, como señalan algunos autores (Bilal y GrossePuppendahl, 2018), existen múltiples cuestiones abiertas respecto a ámbitos como la posible erosión de la influencia de los EEMM, la participación de otras instituciones financieras, la necesidad de reconciliar los objetivos de desarrollo y el papel de los EEMM en la gobernanza del BEI —contando en algunos casos con sus propias instituciones financieras de desarrollo-, posibles complementariedades y solapamientos con el BERD y las instituciones financieras de desarrollo nacionales, operatividad de la gestión, etcétera. Hasta el momento no ha tenido lugar un avance significativo en el debate respecto a posibles cambios en la estructura institucional del banco.

\section{Propuesta de reforma. Nuevo Instrumento de Vecindad, Desarrollo y Cooperación Internacional (IVDCl)}

La aprobación del nuevo marco financiero plurianual para el periodo 2021-2027 está

61 En un contexto de impulso de nuevas instituciones financieras de desarrollo (IFD) a nivel internacional, como FinDev Canada (https://www. findevcanada.ca/) o la propuesta norteamericana de impulsar una nueva IFD reintegrando las actividades repartidas en las instituciones del marco actual(https://www.opic.gov/press-releases/2018/opic-commends-fy2019budget-proposal-modern-development-finance-institution).

62 Bilal y Grosse-Puppendahl (2018). prevista para mayo de 2019. Deberá contar con el voto unánime del Consejo y la aprobación del Parlamento Europeo, con un proceso legislativo iniciado a partir de la propuesta presentada por la Comisión en mayo de 2018 sobre la estructura y las políticas prioritarias ${ }^{63}$ del presupuesto para el nuevo periodo de siete años. Entre los diferentes desafíos destaca el proceso de adaptación, tras la salida del Reino Unido, pasando a una UE de 27 Estados miembros. A pesar de ello, el volumen total propuesto es similar al del marco anterior ${ }^{64}$, entre otros motivos por la «presupuestarización» del FED. La propuesta recoge la financiación de la acción exterior de la UE bajo el capítulo VI, «Vecindad y el Mundo», frente al capítulo IV, «Europa Global», del marco anterior ${ }^{65}$, con una simplificación y reagrupación de los instrumentos existentes en la actualidad. Destaca el objetivo de creación de un Instrumento de Vecindad, Desarrollo y Cooperación Internacional (IVDCI o NDICl, por sus siglas en inglés) —con un importe de 89.500 millones de euros para el periodo. Reagruparía al FED, ICD e IEV, además de a otros como el Instrumento de Partenariado o Cooperación con terceros países, la asistencia financiera y garantías, manteniéndose de forma separada el IPA. Por otra parte, el pasado 14 de junio tuvo lugar la publicación de la propuesta legislativa con el desarrollo de los instrumentos de acción exterior de cara al nuevo periodo, incluyendo el desglose del nuevo IVDCI (Cuadro 5).

Contempla un aumento del presupuesto de acción exterior hasta los 123.002 millones de euros a precios corrientes — sin tener en $\triangleright$

\footnotetext{
63 Incluyendo el nuevo Consenso Europeo para el Desarrollo, el objetivo de erradicación de la pobreza y los Objetivos de Desarrollo Sostenible de la Agenda 2030 de Naciones Unidas.

64 En términos equivalentes - a precios del 2018-, con una propuesta de compromisos de pago de 135.000 millones euros.

65 La nueva estructura contaría con siete capítulos frente a los cinco del marco anterior.
} 
CUADRO 5

PROPUESTA DE INSTRUMENTOS FINANCIEROS DE LA ACCIÓN EXTERIOR DE LA UE27-MFP 2021-2027

\begin{tabular}{|c|c|c|c|}
\hline Instrumentos y partidas financieras 2021-2027 & $\begin{array}{l}\text { Dotación en millones } \\
\text { de euros (1) }\end{array}$ & Media anual & $\begin{array}{c}\text { Peso } \\
\text { (En porcentaje) (2) }\end{array}$ \\
\hline $\begin{array}{l}\text { Instrumento de Vecindad, Desarrollo y Cooperación } \\
\text { Internacional (IVDCl - NDICl) }\end{array}$ & 89.500 & 12.786 & 72,8 \\
\hline Programas geográficos (3) & 68.000 & 9.714 & 55,3 \\
\hline Vecindad & 22.000 & 3.143 & 17,9 \\
\hline África Subsahariana & 32.000 & 4.571 & 26,0 \\
\hline Asia, Oriente Medio y Pacífico & 10.000 & 1.429 & 8,1 \\
\hline América y Caribe & 4.000 & 571 & 3,3 \\
\hline Programas temáticos & 7.000 & 1.000 & 5,7 \\
\hline Democracia y Derechos Humanos (4) & 1.500 & 214 & 1,2 \\
\hline Organismos de la sociedad civil (5) & 1.500 & 214 & 1,2 \\
\hline Estabilidad y Paz (6) & 1.000 & 143 & 0,8 \\
\hline Desafíos Globales (7) & 3.000 & 429 & 2,4 \\
\hline Respuesta rápida & 4.000 & 571 & 3,3 \\
\hline Colchón de desafíos emergentes y prioridades & 10.200 & 1.457 & 8,3 \\
\hline $\begin{array}{l}\text { Instrumento para la Seguridad Nuclear (ISN) comple- } \\
\text { mentario al IVDCI (8) }\end{array}$ & 300 & 43 & 0,2 \\
\hline Instrumento Preadhesión (IPA-III) & 14.500 & 2.071 & 11,8 \\
\hline Ayuda humanitaria & 11.000 & 1.571 & 8,9 \\
\hline Política Exterior y de Seguridad Común (PESC-CFSP) & 3.000 & 429 & 2,4 \\
\hline Regiones y Territorios de Ultramar (incluida Groenlandia) & 500 & 71 & 0,4 \\
\hline Otros & 1.070 & 153 & 0,9 \\
\hline Agencias descentralizadas & 149 & 21 & 0,1 \\
\hline Margen & 3.283 & 469 & 2,7 \\
\hline Total origen presupuestario MFP UE27 2021-2027 (9) & 123.002 & 17.572 & 100,0 \\
\hline $\begin{array}{l}\text { Facilidad de Paz Europea (EPF) —carácter } \\
\text { extrapresupuestario-(10) }\end{array}$ & 10.500 & 1.500 & 8,5 \\
\hline \multicolumn{4}{|l|}{ (1) Sobre el total de origen presupuestario. } \\
\hline \multicolumn{4}{|l|}{ (2) Cifras en precios corrientes. } \\
\hline \multicolumn{4}{|l|}{ (3) Reintegrando el FED, IEV y programas geográficos del ICD. } \\
\hline \multicolumn{4}{|l|}{ (4) Antiguo IEDDH-EIDHR. } \\
\hline \multicolumn{4}{|l|}{ (5) Frente al anterior programa temático de CSO-LA. } \\
\hline \multicolumn{4}{|l|}{ (6) Antiguo Instrumento para la contribución a la Estabilidad y la Paz. } \\
\hline \multicolumn{4}{|l|}{ (7) Frente al anterior programa temático de GCPB. } \\
\hline \multicolumn{4}{|l|}{ (8) Parte del IVDCI ampliado. } \\
\hline \multicolumn{4}{|c|}{$\begin{array}{l}\text { (9) La propuesta de la Comisión para el MPF } 2021-2027 \text { contempla, además, entre los instrumentos de flexibilidad, una reserva de ayuda de emer- } \\
\text { gencia, para cuestiones internas y externas, con la movilización de hasta } 600 \text { millones de euros anuales a precios de } 2018 \text { (equivalentes a } 4.734 \\
\text { millones de euros para el total del periodo 2021-2027 a precios corrientes). }\end{array}$} \\
\hline \multicolumn{4}{|c|}{$\begin{array}{l}\text { (10) Para financiar operaciones militares y de defensa y apoyo en la prevención de conflictos y operaciones de paz, combinando el apoyo ahora } \\
\text { prestado por la Facilidad de Paz para África (APF) - financiada por el FED en el MPF actual- y el mecanismo Athena. El artículo } 41.2 \text { del Tratado de } \\
\text { la UE excluye la financiación de operaciones militares o de defensa del presupuesto UE. }\end{array}$} \\
\hline \multicolumn{4}{|l|}{ Fuente: Comisión Europea y elaboración propia. } \\
\hline
\end{tabular}

cuenta el componente extrapresupuestario señalado en el Cuadro 5- (que implica una media anual de más de 17.500 millones de euros), frente a los 96.768 millones de euros a precios corrientes del marco actual, lo que supone un incremento del 27 por 100. La Comisión ha indi- cado que una vez ajustado por la evolución de los precios, el incremento sería del 13 por $100^{66}$. $\quad \triangleright$

66 No incorpora el efecto de la salida de Reino Unido, por lo que en términos comparables el incremento sería superior. El país representa actualmente un 12,5 por 100 en términos de $\mathrm{GNI}$ — sin tener en cuenta el efecto del Cheque Británico-. 
El peso del capítulo de acción exterior avanzaría hasta el 9,6 por 100 del total del presupuesto ${ }^{67}$.

EI nuevo IVDCI supondrá, de acuerdo con la propuesta, un 72,8 por 100 del importe total, seguido del nuevo IPA — con un 11,8 por 100-, alcanzando los dos principales instrumentos un 84,6 por 100 del capítulo VI. Entre el resto de los instrumentos y partidas (Cuadro 5) destaca el aumento de los recursos destinados a acciones de ayuda humanitaria hasta el 8,9 por 100.

En cuanto a la estructura del IVDCI, este contará con un primer pilar geográfico para la asistencia y cooperación con terceros países (76 por 100 del instrumento) —con especial enfoque en las regiones de África y Vecindad, que suponen conjuntamente cuatro quintas partes del pilar-. El instrumento además ofrece a la región de Vecindad una cierta singularidad respecto de los recursos asignados, umbrales mínimos, programación o un enfoque basado en resultados. EI IVDCI contará con un segundo pilar temático (8 por 100 del instrumento) -que incluye programas destinados a desafíos globales, organismos de la sociedad civil, así como programas continuación del actual Instrumento Europeo para la Democracia y Derechos Humanos y del actual Instrumento para la Contribución a la Estabilidad y la Paz-, con un enfoque multidisciplinar, en un contexto de múltiples desafíos (cambio climático, migración, crecimiento inclusivo...). El instrumento se completa con un tercer pilar para acciones de respuesta rápida (para estabilización y prevención de crisis, refuerzo de la resiliencia de las economías emergentes...) -con 4.000 millones de euros en el periodo-y con un colchón adicional de flexibilidad para hacer frente a nuevas prioridades y desafíos emergentes —con 10.200 millones de euros-.

\footnotetext{
67 Frente a un 8,7 por 100 en el marco anterior, incluyendo al FED.
}

En cuanto a otras medidas específicas, la propuesta legislativa del instrumento recoge umbrales mínimos para determinados objetivos horizontales que pueden estar contenidos en diferente tipo de acciones (25 por 100 en acción climática, 20 por 100 en desarrollo humano, 10 por 100 en migración), así como el objetivo de que al menos el 92 por 100 tenga carácter de Ayuda Oficial al Desarrollo.

Por último, la propuesta del Reglamento del IVDCI incluye también un capítulo dedicado a un nuevo Fondo Europeo de Desarrollo Sostenible reforzado (FEDS+) -a partir de recursos del IVDCI y del IPA-, contemplando la asistencia financiera y la aportación de garantías ${ }^{68}$ con un enfoque geográfico amplio69, como continuación y profundización del reciente Plan Europeo de Inversiones Exteriores.

\section{Conclusiones}

La Unión Europea ocupa un papel protagonista en la cooperación al desarrollo a nivel internacional con una financiación de proyectos a través de un conjunto heterogéneo de instrumentos y facilidades financieras, con una evolución coherente con las estrategias comunitarias y objetivos del Consenso Europeo para el Desarrollo —en línea con la Agenda 2030 de Naciones Unidas-, el proceso de integración y las relaciones exteriores de la UE, destacando la cooperación comunitaria con las regiones de África Subsahariana, Vecindad y países candidatos.

Cabe señalar un uso relevante de mecanismos de gestión indirecta a través de terceros $\triangleright$

68 Con garantías potenciales de hasta 60.000 millones de euros.

69 Frente al enfoque inicial restringido a las regiones de África y Vecindad en la primera fase del PEIE. 
para la ejecución de diferentes tipos de proyectos, con el recurso a mecanismos de cooperación delegada, apoyo presupuestario y nuevas fórmulas de financiación combinada, con un crecimiento notable de la modalidad de blending -habiéndose lanzado diferente tipo de facilidades regionales y temática para la gestión de los recursos y programación de las operaciones lideradas por instituciones financieras acreditadas-. Las donaciones para blending han mostrado un significativo avance, aproximándose al entorno del 10 por 100 del volumen desembolsado por los cuatro principales instrumentos financieros, lo que indica el papel protagonista de esta modalidad, con la búsqueda de un efecto catalizador y movilizador de financiación adicional.

La Comisión Europea ha reforzado la estrategia a favor de la cooperación financiera con el nuevo Plan Europeo de Inversiones Exteriores y el Fondo Europeo de Desarrollo Sostenible para impulsar la inversión privada en los países en desarrollo mediante el uso de garantías, reduciendo los riesgos y generando confianza, con un importante efecto palanca en la movilización de capital adicional de acuerdo con las previsiones de la Comisión.

Por otro lado, la ejecución de proyectos con financiación comunitaria abre la puerta a la participación de empresas en sus procesos de contratación con diferente grado y capacidad de aprovechamiento comercial según el tipo de proyecto, la entidad contratante y procedimientos.

La cooperación comunitaria se acompaña de la actividad del Banco Europeo de Inversiones en terceros países, con un peso relevante de las regiones de Europa no UE y Vecindad Sur en su cartera de préstamos en vigor y nuevas iniciativas destinadas a impulsar su presencia en África Subsahariana. En el pasado reciente han surgido propuestas sobre posibles cambios en la organización y estructura del banco respecto de su actividad extracomunitaria, si bien no ha tenido lugar un avance significativo en el debate al respecto.

Finalmente, la reciente propuesta de la Comisión respecto de la acción exterior e instrumentos para el próximo marco plurianual 2021-2027 recoge un incremento sustancial de las contribuciones en términos nominales, pasando de 13.800 millones de euros a 17.600 millones de euros en media anual a precios corrientes. El capítulo propuesto para la acción exterior de la UE —Vecindad y el Mundo- recoge un volumen sustancial de recursos - de en torno al 10 por 100 del total del presupuesto comunitario-, contemplando la «presupuestarización» del FED y una mayor simplificación y visibilidad con la reintegración de varios de los instrumentos actuales en un instrumento financiero amplio que abarcaría el 73 por 100 de la acción exterior, con umbrales mínimos de actuación en función de diferentes objetivos prioritarios. Como vía de optimización del uso de recursos, la propuesta plantea profundizar en las medidas de cooperación financiera y concesión de garantías existentes en la actualidad, estimulando la participación del sector privado en los proyectos de inversión en los países en desarrollo.

\section{Bibliografía}

[1] ALFIERI, A.C. y SABBATI, G. (2017). Macrofinancial Assistance. PE, EPRS - 607.268, junio. Disponible en: http://www.europarl.europa.eu/RegData/etudes/BRIE/2017/607268/ EPRS_BRI(2017)607268_EN.pdf

[2] BEI (2016). Launch of Boost Africa Initiative, a new integrated approach to boost young innovative entrepreneurs across Africa. Nota de prensa BEl 2016-299-EN, 21 de $\triangleright$ 
noviembre. Disponible en: $h t t p: / / w w w . e i b . o r g /$ en/projects/regions/acp/applying-for-loan/boostafricalindex.htm

[3] BEI (2018). 3.7 billion euros to tackle migration and build resilience in Europe's Neighbourhood - EU Bank welcomes European Parliament vote. Nota de prensa BEI 2018-031-EN, 8 de febrero. Disponible en: http://www.eib.org/en/infocentre/press/releases/all/2018/2018-031-3-7-billion-euros-to-tackle-migration-and-build-resilience-in-europes-neighbourhood-eu-bank-welcomes-european-parliament-vote.htm

[4] BEI (2018). Annual Report 2017 on EIB activity in Africa, the Caribbean and Pacific, and the overseas territories. BEI, Luxembourg. Disponible en: http://www.eib.org/en/infocentre/publications/index.htm

[5] BEI (2018). Financial Report 2017. BEI, Luxembourg.

[6] BEI (2018). The EIB outside the EU - 2017: Financing with global impact. BEI, Luxembourg.

[7] BILAL, S. y GROSSE-PUPPENDAHL, S. (2016). «The EIB's innovative role in ACP countries under the Cotonou Agreement: Options beyond 2020». ECDPM, Discussion Paper n.196, julio. Disponible en: http:// ecdpm.org/dp196

[8] BILAL, S. y GROSSE-PUPPENDAHL, S. (2018). «Reshaping the EU 'private finance for development' landscape». ECDPM Great Insights magazine, Primavera 2018, (vol. 7, ed. 2). Disponible en: $h t t p: / / e c d p m . o r g / g r e a t-i n s i-$ ghts/leveraging-private-investment-for-sustainable-development/reshaping-eu-privatefinance/

[9] CAMDESSUS, M. et al. (2010). Report and recommendations of the Steering Committee of «wise persons». EIB's external mandate 2007-2013 Mid-Term Review. EIB, febrero. Disponible en: http://www.eib.org/attachments/documents/eib_external_mandate_2007-2013_mid-term_review.pdf

[10] CE (2013). Multiannual Financial Framework 2014-2020 and the EU Budget 2014 - the figures. Disponible en: http://www.europarl.europa.eu/greece/resource/static/files/multiannual-financial-framework-2014-2020.pdf

[11] CE (2015). ElectriFI - leading in financing energy access worldwide. Presentación de
Zaccheo, F. (DEVCO C6), 6 de noviembre, Milán. Disponible en: $h$ ttp://anie.it/wp-content/ plugins/acd-attach-document/acd-get-document.php?post_ID=21071\&file_name=presentazione-zaccheo.pdf

[12] CE (2016). Evaluation of blending. CE, Dic. 2016. Disponible en: https://ec.europa.eu/europeaid/evaluation-blending_en

[13] CE (2017). Annual accounts of the European Development Fund 2016, CE, junio. Disponible en: http://ec.europa.eu/budget/biblio/documents/FED/fed_en.cfm

[14] CE (2017). EU Blending and External Investment Plan. Seminario AECID, 21 diciembre, Madrid. Disponible en: http://www.aecid. es/Centro-Documentacion/Documentos/documentos $\% 20$ adjuntos/4.1. $\% 20$ EU $\% 20$ BLENDING\%20AND\%20EIP.pdf

[15] CE (2017). EU Budget Financial Report 2016. CE. Disponible en: http://ec.europa.eu/budget/library/biblio/publications/2017/financialreport_en.pdf

[16] CE (2018). 2017 Annual Report on the implementation of the European Union's instruments for financing external actions in 2016 - Staff Working Document. CE, marzo. Disponible en: https:// ec.europa.eu/europeaid/annual-reports_en

[17] CE (2018). Blending en la UE. Disponible en: https://ec.europa.eu/europeaid/policies/ innovative-financial-instruments-blending_en

[18] CE (2018). Blending Facilities. Presentación de Zanvettor, G. (DEVCO), 18 enero 2018, Bruselas. Disponible en: http://euromediter. eu/wp-content/uploads/2018/02/BlendingFacilities_Jan-2018-1.pdf

[19] CE (2018). Communication from the Commission to the European Parliament, the European council, the Council, the European Economic and Social Committee and the Committee of the Regions -(2018) 321-. A Modern Budget for a Union that Protects, Empowers and Defends the Multiannual Financial Framework for 2021-2027 y Anexos, 2 de mayo. Disponible en: https://ec.europa. eu/commission/sites/beta-political/files/ communication-modern-budget-may_2018_ en.pdf

[20] CE (2018). Questions and answers: the EU budget for external action. Nota de prensa de la $C E$, factsheet MEMO/18/4124, 14 de $D$ 
junio. Disponible en: http://europa.eu/rapid/ press-release_MEMO-18-4124_en.htm

[21] CE (2018). Proposal for a Regulation of the European Parliament and of the Council establishing the Neighbourhood, Development and International Cooperation Instrument (2018) - 460 y Anexos, 14 de junio. Bruselas. Disponible en: https://ec.europa.eu/info/law/ better-regulation/initiatives/com-2018 -460_en

[22] CE (2018). EFDS Operational Report 2018, CE, 11 de julio de 2018. Disponible en: https:// ec.europa.eu/europeaid/sites/devco/files/ efds-report_en.pdf

[23] CE (2018). The EU's External Investment Plan: first projects in Africa and the Neighbourhood. Nota de prensa CE IP/18/4385, 11 de julio. Disponible en: http://europa.eu/rapid/ press-release_IP-18-4385_en.htm

[24] CINCO DÍAS (2018). La UE aprueba el primer proyecto de blending de COFIDES, artículo publicado el 9 de agosto de 2018. Disponible en: https://cincodias.elpais.com/cincodias/ 2018/06/22/companias/1529673264_524254. html

[25] COFIDES (2018). El BEI y COFIDES amplían su colaboración para cofinanciar proyectos en el marco del Blending y el Fondo Verde, nota de prensa, 26 de marzo de 2018. Disponible en: https://www.cofides.es/noticias_detalle.php?id=878

[26] CONSEJO DE LA UE (2018). EU -ACP countries future partnership: Council adopts negotiating mandate, nota de prensa del Consejo 375/18, 22 de junio de 2018. Disponible en: http://www.consilium.europa.eu/ en/press/press-releases/2018/06/22/ eu-african-caribbean-and-pacific-countries-future-partnership-council-adopts-negotiating-mandate/

[27] CUÑAT et al. (2012). «La cooperación de la Unión Europea con terceros países», Revista ICE n.․ 866, mayo-junio. Disponible en: http:// www.revistasice.com/CachePDF/ ICE_866_113-130_02D96F86C74ADAA98E CO025EAB1E2DDA.pdf
[28] DOVREBA, A. (2018). Multiannual Financial Framework 2021-2027: Commission proposal Initial comparison with the current MFF, European Parliament Debriefing, EPRS 621.864, mayo. Disponible en: $h$ ttp://www.europarl.europa.eu/RegData/etudes/BRIE/2018/621864/ EPRS_BRI(2018)621864_EN.pdf

[29] FIOTT, D. y BUND, J. (2018): «Yearbook of European Security 2018", EU Institute for Security Studies (EUISS), mayo 2018. Disponible en: https://www.iss.europa.eu/sites/default/files/EUISSFiles/YES_2018.pdf

[30] JONES, M. y GUARASCIO, F. (2017). «European Investment Bank plans internationally-focused offshoot». Reuters Business News, 6 de diciembre. Disponible en https:// www.reuters.com/article/us-24eu-eib-exc/usive/ exclusive-european-investment-bank-plans-internationally-focused-offshoot-idUSKBN1E02XC

[31] PARLAMENTO EUROPEO (2014). European Development Fund. EPRS - 542.140, noviembre. Disponible en: http://www.europarl.europa.eu/EPRS/EPRS-IDA-542140-EuropeanDevelopment-Fund-FINAL.pdf

[32] PARLAMENTO EUROPEO (2018). EU Budget explained: Expenditure and contribution by Member State - Infographic, marzo. Disponible en: http://www.europarl.europa.eu/news/en/ headlines/economy/20180316STO99923/ the-eu-budget-expenditure-and-contribution-by-member-state

[33] PARRY, M.y SEGANTINI, E. (2014).Development Cooperation Instrument. EPRS - 608.764, octubre. Disponible en: http://www.europarl.europa. eu/RegData/etudes/BRIE/2017/608764/ EPRS_BRI(2017)608764_EN.pdf

[34] UE (2017). Reglamento (UE) 2017/1601 del $P E$ y del Consejo de 26 de septiembre de 2017 por el que se establece el Fondo Europeo de Desarrollo Sostenible (FEDS), la Garantía del FEDS y el Fondo de Garantía del FEDS. Disponible en: https:// eur-lex.europa.eu/legal-content/EN/ TXT/?uri=uriserv\%3AOJ.L_.2017.249.01.0001.01. ENG 